\title{
Research students' conceptions of the role of information and communication technologies in educational technology research
}

\author{
Lina Markauskaite and Dewa Wardak \\ The University of Sydney, Australia
}

\begin{abstract}
The emergence of big data, digital scholarship and eResearch raises the question of how these digital developments in research methods and practices affect research students. This paper presents findings from a phenomenographic study that investigated postgraduate students' conceptions of the role of information and communication technologies (ICT) in research. Ten students conducting research in the broad area of educational technology were interviewed. Three qualitatively different conceptions of ICT in research were identified: complementary, enhancing, and transforming. Results indicate that the three conceptions were closely associated with the expanding students' focus from seeing ICT as a tool in the researchers' hands, to noting that digital technologies may have implications for the process of inquiry, to seeing that ICT has distinct generative capacities and changes the nature of research practices. Findings suggest that students' general understanding of ICT's potential in research is underpinned not by abstract knowledge, but by their practical experiences of how ICT works and their abilities to see how technologies can enhance researchers' individual capacities to generate knowledge in specific situations. Some implications for postgraduate research students' education and capacity building are discussed.
\end{abstract}

\section{Introduction}

Recent years have seen noticeable interest in how digital technologies can contribute to educational research, innovation, and scholarship (Borgman et al., 2008; Greenhow \& Gleason, 2014). Many researchers currently make extensive use of information and communication technologies (ICT) for various aspects of their scholarly work, such as literature reviews, publishing and collaboration (Anderson \& Kanuka, 2003). Some have adopted new forms of data analysis, participatory research and dissemination, such as social network analysis, collaborative video analysis, and Web 2.0 publishing (Greenhow \& Gleason, 2014; Markauskaite, 2010, 2011). Most recently, several new fields of inquiry have emerged at the intersection of digital technologies and educational research, including educational data mining, learning analytics and educational informatics (Collins \& Weiner, 2010; Larusson \& White, 2014; Romero, Ventura, Pechenizkiy, \& Baker, 2010). These all offer new possibilities for investigating various aspects of learning and teaching, particularly for those who work in the broad area of educational technology (Markauskaite \& Reimann, 2014). However, there is concern that innovative ICT-enhanced research practices are not widespread amongst scholars in the social sciences and education, particularly amongst research students (Carpenter, 2012; Markauskaite, Kennan, Richardson, Aditomo, \& Hellmers, 2012; McWilliam \& Lee, 2006).

At the same time, there is increasing concern about the quality and capacity of educational research (Harrison \& Seddon, 2013), including in the area of educational technology (Bulfin, Henderson, Johnson, \& Selwyn, 2014). Educational technology studies are often characterised as being under-theorised, mainly descriptive, lacking methodological rigour and, eventually, failing to contribute to the scholarship or influence educational practice (Bennett \& Oliver, 2011; Maddux, 2003; Randolph, 2007). Recent evidence reveals that many researchers who do research in the area of educational technology lack skills in using advanced qualitative and quantitative data collection and analysis methods (Bulfin et al., 2014). Most alarmingly, many of these researchers are not even comfortable understanding methodologically advanced studies done by others.

The emergence of big data and new ICT-enhanced research techniques is seen as an opportunity to fix some common issues in educational research (Eynon, 2013; Markauskaite, 2011). In the educational technology domain specifically, there is a strong expectation that researchers, particularly emerging scholars, will be willing and able to embrace ICT-enhanced research (Greenhow \& Gleason, 2014). However, there are also warnings that ICT-enhanced research may become a new challenge for research 
capacity building. For example, there have been concerns that some novices hold the misconception that "software is a method" (Gilbert, Jackson, \& di Gregorio, 2014), and that researchers lack awareness of what can and cannot be done by using big data or by adopting ICT-enhanced analytical methods (Eynon, 2013; Reimann, Markauskaite, \& Bannert, 2014). Nevertheless, it remains largely unknown how researchers, particularly research students, actually make sense of the potential of these digital research developments to contribute to educational technology research.

An understanding of students' conceptions has been regarded as vital for effective change and innovation in higher education. As Ellis and Goodyear (2010) stated, students are active interpreters of their environment, its culture, values and challenges; to foster sustainable change, it is necessary to understand how learners see and interpret those larger environments that they encounter.

How do research students make sense of ICT-enhanced research and the role of new technological affordances in scholarly practices? Understanding students' ways of seeing the role of ICT in research could illuminate how and why they do, or do not, use ICT in their research, and how their learning and inquiry experiences could be enhanced.

To answer the above question, we investigated postgraduate students' conceptions of the role of digital technologies in research. We focused on master and higher research degree students carrying out research dissertations in the area of educational technologies. We adopted a phenomenographic approach (Marton, 1986, 1994) and aimed to answer three specific research questions:

(1) How do students perceive the role of ICT in research?

(2) How do students perceive the role of ICT in the main aspects of the inquiry cycle: data gathering, data analysis, collaboration, dissemination and access to information?

(3) How do students perceive the relationship between traditional and ICT-enhanced research practices?

By answering these questions, we make three main contributions. First, we provide empirical evidence for the discussion of research capacity within the field of educational technology, by demonstrating that these research students hold a variety of conceptions about ICT's roles in research. While generally acknowledging ICT's utility, not all conceptions recognise its larger innovative potential or conceive ICT as an inherent part of research. Second, we provide evidence that students' conceptions about innovative ICT's roles in research are not necessary rooted in radically new technological applications, but stem from students' awareness of the potential for even general-purpose applications to change conventional research practices and outcomes. Building on this finding, we extend the literature on technological innovation, and argue that key transformation occurs not only in technologies, and not only in ways of using existing technologies, but in practices for which technologies are used. Third, we propose that students' conceptions of transformative ICT's potential in research draw on a rather different view of the relationship between the researcher's capacities, the powers of ICT and research activity. This way of seeing capitalises on the generative potential to create new knowledge that emerges from the networked interplay of human capacities, epistemological frameworks, data, software applications and contexts. We discuss some instructional approaches that could assist students to develop this dynamic way of thinking, such as networked learning, research apprenticeship and open research projects.

The paper is organised as follows. Initially, we introduce current notions of ICT in educational technology research and our adopted definition of ICT-enhanced research. Then, we elaborate on our reasons for focusing on research students' conceptions. For this, we present some key ideas on the role of conceptions from the phenomenographic literature and an overview of related claims regarding how technologies change human practices and experiences from the sociological literature. Then, we provide a detailed review of empirical studies that focused on research students' attitudes and practices related to the use of ICT in research. Subsequently, we introduce the phenomenographic research approach and outline the design of our study, followed by a presentation of the results explicating students' conceptions of ICT's role in research. We finish with the discussion of the main findings and implications. 


\section{Background and literature review}

\section{Current notions of ICT in educational technology research}

The notion of ICT-enhanced research in education has mainly been associated with an acknowledgement that digital technologies can enable new research approaches based on cross-disciplinary theorisation, collaborative design, data-rich inquiry, visualisation and new forms of research dissemination (Eisner, 1997; Greenhow \& Gleason, 2014; Smeyers \& Depaepe, 2007; Voithofer, 2005). In the field of educational technology, the potential of ICT has been particularly strongly associated with increasing volumes of e-learning data. As Borgman and colleagues (2008) point out:

[A]s more human communication takes place in the networked world for education, commerce, and social activity, an extensive digital trace is being created, a deluge of behavioral data. These data are extremely valuable for modeling human activity and for tailoring responses to the individual - whether for learning or for commerce ... these vast amounts of data allow scholars to ask new questions in new ways, and teachers to assess learning in new ways (p. 24).

However, ICT-enhanced research practices in this field are diverse (Markauskaite \& Reimann, 2014). Many researchers have adopted digital technologies to support conventional research practices, such as online library databases, online surveys, and software for qualitative and quantitative data analysis (e.g., NVivo, SPSS) (Gilbert et al., 2014; Knezek \& Christensen, 2014). Others have deployed novel approaches, such as online social network analysis (Dawson, 2008), data mining (Romero et al., 2010) and a range of other learning and teaching analytics techniques (Markauskaite \& Reimann, 2014). Accordingly, notions of what counts as ICT-enhanced research range from "weak" to "strong" interpretations (Markauskaite, 2011). The strong interpretation - exemplified by the rise of "big data" (Eynon, 2013) and "the fourth paradigm" (Hey, Tansley, \& Tolle, 2009; Markauskaite, 2010) - asserts that such research practices mainly include the use advanced high-speed computer networks, large datasets, and specialised research tools. The weak interpretation - represented by the notion of "new digital media research" (Voithofer, 2005) - claims that such new research practices are not restricted to specific tools, and could include the use of any digital technology and software, including email, web browsers, spreadsheets and other general-purpose software.

Furthermore, views about what constitutes the scope of ICT-enhanced research range from "narrow" to "broad” (Markauskaite, 2011). From a narrower perspective, ICT-enhanced research is often understood as encompassing just core aspects of research method, including digital data gathering (e.g., online surveys, eye tracking, digital logs) and data analysis (e.g., data mining, video analysis, statistical analysis and modelling). From a broader perspective, ICT-enhanced research can be viewed as encompassing all aspects of the knowledge-production cycle and scholarship, from research planning through to dissemination of findings, to collaboration and engagement in open innovation (Greenhow \& Gleason, 2014).

In this study, we adopted the most inclusive notions of ICT and ICT-enhanced research. Being open to various interpretations and various uses of data, networks and technologies in scholarly practices, we defined ICT in the broadest possible sense, to include digital devices, networks, data, general-purpose and specialised software, standalone applications and networked tools. Rather than providing participants with a detailed definition of what counts as ICT, we inquired of students how they construed ICT and its role across the full spectrum of research practices, from data gathering through to analysis, dissemination and collaboration. The adoption of this inclusive approach allowed us to investigate and understand students' conceptions of ICT and ICT-enhanced research, which was the main aim of our study.

\section{The role of conceptions in understanding technologies in research practices}

According to Marton and Pong (2005), conceptions are “ways of seeing”, "ways of conceptualising”, "ways of experiencing”, "ways of apprehending” and "ways of understanding” phenomena (p. 336). People experience and conceptualise phenomena differently; how they deal with situations is influenced by how they experience them (Marton \& Booth, 1997). These ways of seeing and conceptualising are related to how the individual approaches the phenomena, such as inquiry and research (Åkerlind, 2008; 
Brew, 2001; Ellis \& Goodyear, 2010; Meyer, Shanahan, \& Laugksch, 2005). For example, Brew (2001), who studied senior researchers' conceptions of research, argued that researchers' conceptions are closely associated with what they do:

Whenever a process of inquiry is talked about or engaged in, what is said and done is dependent upon underlying conceptions about the nature of research. These influence the types of projects researchers feel comfortable in pursuing, the choice of methodology, the questions, ideas and issues pursued, and the ways in which the work is carried out. (p. 283).

Biggs (1999) claimed “our conceptions of phenomena change, and we see the world differently” (p. 60). That is, conceptions are dynamic and relational phenomena, and one can learn (or be taught) to perceive and approach situations differently. However, the acquisition of information in itself does not bring conceptual change, rather it is how people structure information and the way they think about it that changes how they see and approach the phenomena (Biggs, 1999). ICT is a phenomenon whose embracement is found to depend hugely upon one’s way of seeing (e.g., Ellis \& Goodyear, 2010).

Sociological literature has persuasively argued that ICT is not a neutral medium or tool in research; rather it significantly changes inquiry practices and experiences (Gunter, Rowlands, \& Nicholas, 2009; Voithofer, 2005). Moreover, scholars have claimed that its use in research may represent a very substantial epistemological shift, as digital media, communication networks and computational affordances enable paradigmatically different forms of inquiry and scholarship (Hey et al., 2009). For example, Greenhow and Gleason (2014) argue that social media, by providing technological affordances that permit capitalising on values and qualities of openness, conversation, access, sharing, and transparent revision, have a potential to transform the ways in which academic scholarship is defined and accomplished.

Researchers also note that technological change and innovation in practices may occur in two ways (Gunter et al., 2009). Transformative innovation is when a new technology emerges unlike any other in existence. People have to figure out how and for what purposes to use it. General-purpose innovation is when existing technologies undergo a transformation, not in technical features, but in how they are used. Further, the potential benefits of all innovations are often accompanied by various personal concerns, such as personal cost, trust, and logistics (Hall, 1979). These concerns are shaped by, and shape, people's ways of seeing and embracing change.

In all cases, as Orlikowski (2007) argues, the properties of technologies are not embodied in media; instead they are multiple, shifting and, in essence, emerge from the interaction between human sensemakers and technologies in unfolding practices. How people see technologies in their practices, and what kinds of capacities they ascribe to these tools, play a constitutive role in how eventually they enact them. Therefore, the understanding of research students' conceptions of ICT in research plays an important role in recognizing what kinds of powers students assign to ICT; and, subsequently, why students embrace or do not embrace technological affordances in particular ways.

\section{Students' attitudes and approaches towards the role of ICT in research}

Some studies have investigated researchers' and students' attitudes and approaches to using ICT (Barjak et al., 2009; Dutton \& Meyer, 2009; Esposito, 2013; Hine, 2006; Jankowski, 2009). These studies identified several mutually constituting factors influencing researchers' beliefs about the use of ICT in their scholarly work, such as experience with ICT, the nature of research practices, and contexts. For example, Dutton and Meyer (2009) found that experience with ICT and intellectual engagement with eResearch developments were the most influential factors for research technology adopters. They also noted that recent $\mathrm{PhD}$ graduates were most comfortable in adopting new ICT-enhanced research approaches, because they had used the Internet and/or other related ICTs during their doctoral education.

Only a few recent studies specifically look into how postgraduate research students conceive and approach the use of ICT in their research (Beames, Klenowski, \& Lloyd, 2010; Carpenter, 2012; Stelma, 2010). One of the largest of these, tracking three years' research behaviour of Generation $Y$ doctoral students, found that research students were highly competent ICT users and sophisticated information seekers; however, they were quite risk averse and conservative about embracing new technologies in their 
research (Carpenter, 2012). Students tended only to adopt new applications if they saw their immediate utility, and preferred familiar tools that fitted with their existing research practices. These students were not particularly keen to collaborate or openly share their research outputs, and shared their research only with their work colleagues. The study concluded that a lack of ICT skills tended not to be the main reason for the marginal students' use of ICT in their research, but that an obvious obstacle was a lack of awareness of how ICT and more open collaboration might fit into their doctoral practices.

Other studies suggest that experience with ICT and a familiarity with practice may play constitutive roles in embracing new technological affordances. For example, Beames et al. (2010) observed a group of education doctoral students abandon a specially designated collaborative wiki and instead use more traditional group emails to form a support network around their tasks. Stelma (2010) similarly observed that doctoral students used already familiar software programs to gain better understanding of their research data. Nevertheless, he also found that these students were not resistant to change and mixed familiar tools with newly learnt specialised research software in innovative and intentional ways. Stelma (2010) argues that students' exploration of new research software was guided by both the potential relevance of some new software affordances for the aims of their doctoral projects, and also by the resources and expectations about the use of software present in students' research environments (including personal, peers', supervisors' and institutional support and expectations).

Overall, most studies agree that researchers' and students' beliefs about how ICT fits with, and could enhance, their research is one of the major factors contributing to their decisions on how to use ICT. However, despite widespread public acknowledgement that ICT-enhanced research holds enormous potential to enhance inquiry within the domain of educational technology, empirical evidence about researchers' and research students' views and experiences of ICT-enhanced research has been minimal. Overall, the importance of their perspectives in developing this research area has been largely overlooked.

\section{Methodology and study design}

\section{Phenomenography}

This study adopted a phenomenographic research approach commonly used for researching conceptions (Marton, 1986, 1994). The focus of such research is on the variation in ways of experiencing something. People encounter and experience phenomena in a certain number of qualitatively different ways (Marton \& Booth, 1997). Experience has the general connotation of “anything lived or undergone” (Peplau, 1957, p. 884). However, in some traditions of phenomenographic inquiry, the word has a broader meaning that includes ways of seeing, understanding, comprehending, apprehending and conceptualising a phenomenon, irrespective of one's direct encounter of that phenomenon (Bowden \& Green, 2005; Marton \& Pong, 2005).

People's experiences are related to their contexts, but share some common characteristics. In phenomenographic research, the different ways of experiencing are represented in the form of categories of description (Marton \& Booth, 1997). An experience has two intertwined aspects: a referential aspect and a structural aspect. The referential aspect is a particular meaning given to an individual object, and the structural aspect is the structure of features the subject focuses on. The structural aspect comprises internal and external horizons. As Marton and Booth (1997) state, to experience something we have to discern it from the outside context. This is called the external horizon. In contrast, the internal horizon is discerning the parts of a phenomenon, how they relate to each other and to the whole.

There are several distinct phenomenographic traditions (see Bowden \& Walsh, 2000); we adopted Marton's $(1986,1994)$ approach, which does not require that the phenomenon being investigated must necessarily be directly encountered by participants beforehand (Marton \& Pong, 2005). We anticipated that some students might not have authentic experience of using ICT in all aspects of research, given the relative newness of ICT-enhanced research practices, thus we regarded Marton's $(1986,1994)$ approach as the most suitable for investigating students' conceptions in this domain. 


\section{Participants and the procedure}

The study was conducted at an Australian research-intensive university, and approved by its human research ethics committee. Participants were selected using purposive sampling (Bowden \& Green, 2005) from students who had been conducting research in an area associated with ICT use in education. Open invitations describing the study and asking for voluntary participation were sent to a mailing list of higher research degree students with research interests in computer-supported learning and postgraduate students in programs related to learning technologies. Ten of those who responded met sampling criteria (i.e., did a dissertation in a relevant area) and were invited to participate (Table 1). The final sample comprised five male and five female students; eight were working on master's dissertations and two were enrolled in higher research degrees. Participants' ages varied from mid-twenties to late-fifties. All had some interest in, and experience with, ICT - that is, they usually used ICT in their professional fields - but they came from a variety of disciplines and professional backgrounds. Three participants had some research experience, and others were doing their first research study. They were at different stages: from deciding about their study's focus to analysing data and writing. Their research topics covered a broad range of areas related to ICT use in education. While some characteristics were not evenly distributed across the sample, the variation in participants' backgrounds and experiences was wide-ranging and appropriate for phenomenographic study (Bowden \& Green, 2005).

Table 1

Summary of the study sample

\begin{tabular}{|c|c|c|c|c|c|}
\hline Participant & Gender & Level & $\begin{array}{l}\text { Type of } \\
\text { student }\end{array}$ & $\begin{array}{l}\text { Professional } \\
\text { background }\end{array}$ & Research area \\
\hline $\mathrm{P} 1$ & Female & Master & International & TESOL* & $\begin{array}{l}\text { Online discussion for } \\
\text { language learning }\end{array}$ \\
\hline P2 & Male & Master & Domestic & Teaching ICT & $\begin{array}{l}\text { Teachers' conceptions of } \\
\text { online discussions }\end{array}$ \\
\hline P3 & Male & Master & International & TESOL* & $\begin{array}{l}\text { Content analysis of learning } \\
\text { technology journals }\end{array}$ \\
\hline P4 & Male & EdD & Domestic & $\begin{array}{l}\text { Information } \\
\text { technology }\end{array}$ & $\begin{array}{l}\text { Sustainability education and } \\
\text { educational technologies }\end{array}$ \\
\hline P5 & Male & Master & Domestic & Teaching ICT & ICT use in high schools \\
\hline P6 & Female & $\mathrm{PhD}$ & Domestic & e-learning design & $\begin{array}{l}\text { Higher education policy and } \\
\text { practice }\end{array}$ \\
\hline P7 & Female & Master & Domestic & e-learning design & $\begin{array}{l}\text { Preliminary stages, } \\
\text { organizational learning }\end{array}$ \\
\hline P8 & Male & Master & Domestic & $\begin{array}{l}\text { Coordinating online } \\
\text { courses }\end{array}$ & $\begin{array}{l}\text { Preliminary stages, not yet } \\
\text { decided }\end{array}$ \\
\hline P9 & Female & Master & Domestic & $\begin{array}{l}\text { Curricula } \\
\text { development }\end{array}$ & $\begin{array}{l}\text { Online social networking in } \\
\text { tertiary education }\end{array}$ \\
\hline P10 & Female & Master & Domestic & e-learning design & $\begin{array}{l}\text { Social networking for } \\
\text { informal workplace learning }\end{array}$ \\
\hline
\end{tabular}

Note: * TESOL stands for Teaching English to Speakers of Other Languages.

The phenomenographic literature recommends samples of 15 to 30 participants, but acknowledges that smaller sample sizes could be appropriate (Bowden \& Green, 2005). In particular, phenomenographic studies investigating new domains often have much smaller samples; for example, phenomenographic studies of e-learning, blended learning and information literacy drawing on just three to seven participants (Forster, 2013; Gonzalez, 2009; Roberts, 2003). Given our focus on the specific research domain of educational technology, extensive coverage of students with relevant research interests and experiences, and lack of previous studies in this area, ten participants was considered an acceptable sample. 
Figure 1 shows the conceptual framework of the study design. Phenomenographic interviews consisted of a set of semi-structured questions about key aspects of ICT-enhanced research. Students were first asked to reflect on the role of ICT in research and the changes ICT brings to research practices in general. Then, they were asked to discuss ICT's role in specific aspects of the research knowledge cycle (Markauskaite, 2010). The former question aimed to investigate the referential aspect and distinguish the external horizon in the structural aspect, while the latter set of questions aimed to gain insights into the internal horizon of students' experiences. To ensure research rigour, quality and trustworthiness of data, the participants were also asked probing follow-up questions such as, "What do you mean by that?" or "Can you explain more?”

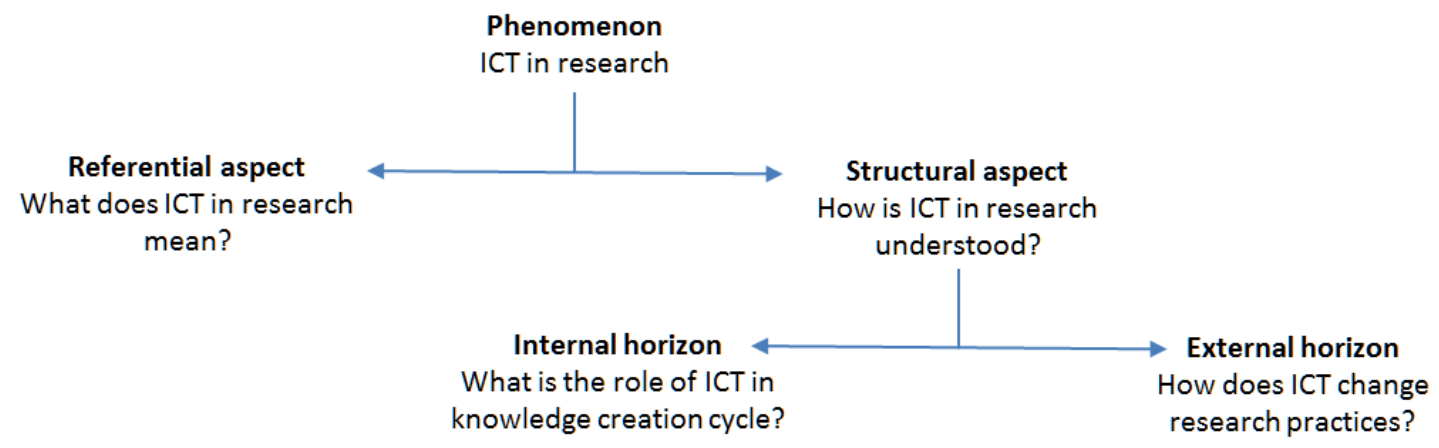

Figure 1. Conceptual framework of the study design

\section{Data analysis}

Data analysis employed procedures proposed by Marton $(1986,1994)$ and was conducted using NVivo software. The analysis started after all interviews were completed and transcribed. "Phenomenographic research aims to explore the range of meanings within a sample group, as a group, not the range of meanings for each individual within the group” (Åkerlind 2008, p. 117); accordingly, the initial pool of meanings was constructed from all the transcripts by categorising data based on common ideas expressed by all participants, without focusing on specific participants or parts of the interviews. Each quote was then interpreted in relation to the pool of meanings, to see what others had said about the same thing, and in relation to individual transcripts, to see what the person had said about other issues relating to the topic. The process took into account all meanings expressed by participants about different aspects of research, irrespective of the structure of the interview, thereby reducing the risk of taking utterances out of their original interview context. To maintain the research rigour and quality of the findings, two researchers initially separately examined the pool of meanings and assigned the participants' expressions to the categories of descriptions. Then they discussed and refined their interpretations iteratively in several meetings. In the final outcome, each category and each dimension of variation was represented by a number of quotes from multiple participants of varying backgrounds. This result shows that this sample and procedure resulted in sufficient “data saturation” (Bowden \& Green, 2005).

\section{Results}

\section{Students' conceptions of the role of ICT in research}

Three interrelated categories of description, exhibiting qualitatively different ways in which research students understood ICT's role in educational research, were identified:
A. ICT complements research
B. ICT enhances research
C. ICT transforms research. 
Each category and the relationships amongst them are described below.

Category A: ICT complements research

In this category, ICT's role in research is viewed as complementary. ICT is seen as providing the means for a researcher to do the job and as mediating the process of inquiry. Nevertheless, technologies neither replace the power of the human mind, nor enhance researchers' capacities to generate new findings. For example, one participant stated:

I am using ICT all the time (.) and (.) for my research I haven’t started using NVivo for the analysis stage yet but it is interesting because the analysis can be done without the need for NVivo (.) in terms of using it as a tool for research (.) I guess in essence to me seem to be the application of ICT in order to achieve research. [P2]

(Note: We use the following notations in quotes: (.) - a micro pause, a notable pause but of no significant length; (n) - a longer pause of $n$ seconds; (...) - an abbreviated text; [Explanation] - an explanation added to a quote.)

Thus, ICT is seen as an instrument researchers might choose to use to achieve something that could be done without ICT. Established ways of knowing take precedence over the role of ICT. For example, two participants expressed this view by comparing the role of ICT in data analysis to the role of calculators in traditional maths classes, arguing that students should first learn to calculate without a calculator. While this view generally recognises potential benefits of ICT, it sees their scope as limited to the technical improvements of tools that do not really alter research practices or outcomes.

\section{Category B: ICT enhances research}

In this category, ICT is discussed as extending and enhancing existing research processes. Participants referred to ICT as a tool with the potential to enhance human capacities and make research faster, easier, broader, and overall better. The main idea guiding this view is that existing research practices can significantly benefit from the use of ICT; however, technologies neither change the form of inquiry, nor the nature of the research questions pursued. Rather, ICT brings efficiency, flexibility and a larger scope to traditional research. The following quotes exemplify this category:

ICT probably allows a broader scope in research. [P7]

It would be a bit quicker to get something published. [P10]

Participants often used comparative adverbs to describe the role of ICT in research, such as "easier", "faster", "quicker”, "broader”, “more accessible” and "more flexible”, signalling that ICT is not just an insignificant replaceable instrument, but a tool that enhances what researchers already do.

Category C: ICT transforms research

In this category, ICT-enhanced research is discussed as a different, transformative way of doing research not possible without ICT. This includes new data types, new forms of instantaneous collaboration across long distances, new ways to analyse data, and new ways to record and display information. At the core of this view is the notion that ICT brings new capabilities and enables innovative research practices that are only possible with ICT.

Participants were aware that digital data, representing educational phenomenon, are complex, abstract and much larger than data obtained manually; they therefore require ICT-enhanced analytical techniques and tools. For instance, one participant stated:

The software is invaluable (.) because I can use it to generate statistical models things which the human mind can't really grasp because it is rather abstract (.) so the software is invaluable. [P3]

Participants often used superlative phrases to express their points of view, such as "ICT is central" [P9], "ICT has completely changed absolutely everything about research" [P6]. Students also referred to some research methods that would be impossible without ICT, such as simulation. Overall, the way of seeing 
represented by this category was that ICT is not an epistemically neutral media or tool, but has the capacity to bring to light new forms of inquiry and change the nature of research practices.

\section{How ICT in research is understood}

To gain further insight into the nature of students' conceptions of ICT-enhanced research, we explored the internal and external horizons. The internal horizon was defined by how the participants saw the role of ICT in the main elements of the research cycle: data gathering, analysis, collaboration, dissemination and access to information. These provided five dimensions of variation for exploring the structure of ICTenhanced research phenomena. The external horizon was defined by how the participants described the place of ICT in relation to the researcher and research activity. The main dimension of variation here was how participants described an agentic role of ICT. Each dimension in the internal and external horizons was explored by identifying the main features characterising students' conceptions and relationships between these features.

\section{Dimension 1: Data gathering}

The variation in this dimension represents an expanding focus from the technical features, in Category A, to the distinct epistemological qualities of digital data, in Category C.

In Category A, ICT is seen as a source and a tool. In this view, ICT provides a range of digital instruments for collecting diverse, good technical quality data, some of which would be difficult to capture without ICT. Such data could be useful additional evidence. For example, participants commented:

ICT helps you substantiate all, gather the evidence that you need to prove what you are saying. [P5]

In Category B, the focus expands to the distinctive role of ICT in gathering data, particularly to the new data collection techniques. This view recognises that ICT improves not only the technical quality of data, but also the efficiency of the data-collection processes: it is easier to collect data; it is faster to prepare data for analysis; it is possible to collect data from a larger number of participants, etc. This category recognizes that ICT may help to collect more data, and consequently may enhance the scope of studied phenomena. For instance, participants stated:

I think it means that you can get more, a wider range of people to respond to research. You don't necessarily have to have them in the same room as you. So perhaps you can manage to get more participation because you don't need them to be in a particular place in a particular time. [P9]

In Category $\mathrm{C}$, the focus shifts to the epistemic features of data. In this view, digital data-gathering techniques allow for the study of new types of educational phenomena, such as investigating online learning using students' learning logs; or studying $\mathrm{PhD}$ students' journeys by researching their personal blogs. These techniques also enable evidence to be collected from people who might otherwise be excluded. Most importantly, digital formats enable the management, manipulation, and analysis of data in ways that would be impossible without ICT. The emphasis on these distinct features of digital data represents a shift from the technical to the epistemic qualities of data that enable research to be done differently and to discover new findings. The following quote exemplifies this view:

[T]he size of data that you can capture, the number of people, the geographically dispersed nature of people and the ability for ICT to capture data from those people (.) Yes, it is the ability of ICT to learn to video, to capture video, to manipulate images, audio. (3) Depending on what the research is, this is enormous. [P8]

\section{Dimension 2: Data analysis}

This dimension shows an expanding focus from the view that ICT provides tools for data analysis to the understanding that ICT influences the nature of data analysis and outcomes. 
Category A represents students' views of ICT-enhanced data analysis as the use of helpful and reliable digital tools. Excel, Word, NVivo, SPSS and modelling software were some examples of software products mentioned by participants that could be used for analysing educational data. However, in this category, ICT tools do not necessarily make a qualitative difference to how data are analysed or to outcomes. Participants reflected:

It reminds me of a calculator in mathematics and I remember maths teachers telling me you know don't use the calculator try and do it by hand first and then come and do it with the calculator and you will see what the calculator is doing if you do it by hand. Um, so I think about that when I think about eResearch. [P2]

In contrast, Category B focuses on how ICT enhances analytical techniques and methods. For example, participants noted its role in providing possibilities for direct audio and video analysis without transcription, or to analyse data using 3D modelling. This view is closely related to the use of ICT tools; however, the emphasis shifts to those qualities of the technologies that make the process of ICT-enhanced data analysis more efficient and powerful: "it will be much easier and faster to do data analysis" [P1]. The main focus is on those kinds of analyses that would be hard to do without the use of ICT-enhanced techniques.

Finally, Category C represents students' views that primarily focuses on the nature of the analytical practices and outcomes. ICT not only enhances techniques, but also mediates inquiry by enabling new analytical approaches and processes, "which the human mind may not be able to achieve” [P8]. Such data analysis could result in qualitatively different findings.

\section{Dimension 3: Research collaboration}

This dimension represents the expansion of the view of ICT's role in research collaboration from providing physical tools and connectivity to enabling distinct models of collaborative research.

In Category A, ICT is discussed as a set of network technologies that provide helpful tools and connectivity for research collaboration, such as text and audio chat, video conferencing, email, blogs, social networking sites and specialised collaborative software. In this category, ICT provides the complementary means for organising work, staying in touch, sharing ideas and materials, but does not necessary change the nature or extent of existing collaborative practices. For example, participants reflected:

I tend to use it (.) ICT as a tool to do more effectively what we already do, so I can have a (.) we can all have our manual diaries and arrange meetings or we can use a bit of technology (.) that we can collaborate on and it does it for us, but it's not really doing anything very different to the document. [P4]

In Category B, the focus shifts to the role of computer networks in overcoming time and physical constraints, thus enhancing the scale and scope of possible collaborations. In this category, the participants often referred to the enriched possibilities of collaborating internationally and avoiding travelling. The main focus is expanding possibilities to work together, including "with someone that's on the other side of the world" [P7].

In Category C, the focus expands further to include the nature of relationships and new knowledge cocreation practices. In this category, ICT-enhanced collaboration is less formal and more driven by joint interests, openness, communal values, and personal motivation. The main focus is not so much on the size or scope of collaboration, but on the opportunities to surpass social constraints, connect diverse ideas, and co-construct knowledge jointly:

[I]t is always that collaborative thing (.) like you would have never thought of something that someone else thinks of ... [P5]

Dimension 4: Research dissemination

This dimension represents the gradual expansion of the focus from the technical features and affordances of digital media to the social models of research dissemination. 
In Category A, ICT is seen as media that offer more options for research dissemination to include additional media forms and channels. For example, the majority of participants indicated that researchers now have the option to publish in online journals, in their personal blogs, or even on Twitter. These options are seen as a useful complement to traditional publishing and dissemination. However, in this category, the emphasis is on new technical features and options rather than their impact on the nature of dissemination.

In Category B, the role of ICT is less characterised by the new media features than by their implications on the dissemination process. ICT provides means to disseminate research easier and faster while also allowing dissemination on a broader scale. (The latter aspect primarily refers to the location and number, rather than characteristics, of the people that can access and benefit from research outcomes.). The following quote exemplifies this view:

[R]esults can be published much faster now, rather than waiting for a journal to be compiled and edited and then sent out, it can now happen very rapidly. [P4]

Category C represents the role of ICT as enabling different models of research dissemination, such as publishing preliminary results, and non-peer-reviewed findings; and mixing dissemination with collaboration during the entire research cycle. ICT allows different audiences to be reached who would not normally access and read traditional peer-reviewed journals. The emphasis is on changes in the traditional scholarship practices.

Dimension 5: Access to information

The participants in this study were not directly asked to express their opinion about the role of ICT in accessing information. However, eight students discussed availability of digital information for general research purposes (e.g., literature review). As this role of ICT was different from the access to information for data gathering (e.g., access to published articles for discourse analysis), students' views about access to information for general research purposes were analysed separately. In this dimension, students' views varied from seeing digital information as mirroring traditional information to seeing ICT as fundamentally changing access to information.

Category A represents the view that digital resources complement access to information, but similar information could be accessed without the use of ICT. That is, the digital format simply offers an alternative means, but does not necessarily contribute to an increase in the quality or scope of access.

Category B focuses on the magnitude of information available. Online resources, such as e-journals, facilitate access to large numbers of articles and a wealth of information. However, access to large amounts of information is not always perceived as a positive trait as this sometimes could result in information overload and confusion. For example, participants observed:

I think with ICT and the availability of article journals you tend to go and get all of them so you end up with a huge number of articles that may or may not be very useful to you. [P9]

In Category $\mathrm{C}$, the focus shifts to the nature of the information available. There is a fundamental difference between printed and digital formats. For example, many people can access electronic articles at any one time without limiting access for others. As one participant commented about digital books and journals: "[N]ow everyone can have the same copy. There is no scarcity” [P3].

\section{Dimension 6: Agency in ICT-enhanced research}

This dimension of variation characterises the external horizon and shows how students perceive ICTenhanced processes in relation to conventional research practices. It represents a shifting perception of ICT's agency in research from affiliative, in Category A, to agentive, in Category B, and to a generative role, in Category C.

In the affiliative view, students attribute agency to the researcher, who fundamentally shapes the course of the inquiry, with ICT playing a secondary role. ICT is seen as an instrument in human hands, and the 
researcher can fully control both its positive and negative effects. The participants often expressed this view by referring to well-established practices and routine ways of using ICT.

I think it is very important when we're using ICT to say at the beginning, to get a feel for the patterns ourselves and then can use ICT to confirm (...) which we then look at and make informed decision ourselves, not just totally reliant on it. [P4]

In the agentic view, digital technologies are seen as a phenomenon already in existence that proactively shapes and destabilises various aspects of inquiry practices. Their role is often viewed as positive and as augmenting inquiry; however, agency is considered to be embedded in the ICT tools and, as such, the benefits of their use are not always transparent and the impact cannot always be controlled.

If you are going to build models using modelling software (...) what are assumptions and the formula that you include to do that, and are they going always to be correct. And then there are technical limitations; so what happens if everything crashes. [P8]

Many participants had concerns not only about the danger of making mistakes or hardware and software failures, but also about the social inequity that ICT brings to research and the constant need to "catch up" with evolving technologies. Students' agentic views were often expressed using general and less certain statements (e.g., "probably”, "potentially”, “perhaps”), which were not necessarily linked to their concrete experiences.

Finally, in the generative view, ICT is seen as a constructive device that plays an active role in inquiry. Technologies are neither transparent nor predictable (unlike Category A); nor do they dominate and destabilise the research processes (unlike Category B). In this view, ICT has affordances that enable certain research practices and constrain others. The course of inquiry and the findings emerge from a dynamic interaction between the researcher's aims and skills, the affordances of the ICT, and the context.

Well, NVivo absolutely invaluable. NVivo (3) Also (.) I do use Excel a little bit more for record keeping. I have spreadsheets with all sorts of information which I can find (.) when I put in spreadsheet often forms a pattern, but NVivo would be my main way of slicing and dicing the data, (.) keeping it there making connections between things. [P6]

In this category, participants rarely discussed ICT's role in absolute terms. Rather, they paid significant attention to the situations and contexts in which ICT makes a difference, such as changing research arrangements and increasing time pressures.

\section{Relationships between the dimensions of variation}

All the participants expressed a range of views about the role of ICT in research. We observed hierarchical relationships between categories similar to those found in other phenomenographic studies (Gonzalez, 2009; Marton \& Booth, 1997). Further, our results showed several distinct features of students' views. First, the external and internal horizons were closely interrelated and the five dimensions of the internal horizon were usually expressed within the external horizon. For example, students' concerns about negative effects of technologies, which were associated with the affiliative view of ICT, were expressed not only in students' views about data analysis, as was illustrated above, but also in their views about collaboration:

[T]he disadvantages are (.) I think you are eliminating people from your research group who can't use (.) or who don’t feel comfortable using ICT, which means you could be missing on out valuable input or a person to join a team. [P6]

Second, students' conceptions were not the same across all dimensions of variation. Table 2 summarises students' views. For example, student P4's description of the role of ICT in data gathering, analysis and collaboration predominantly reflects the complementary conception (Category A); but her views about ICT's role in dissemination and access to information mainly reflect the enhancing conception (Category B). Only four students (P2, P5, P6 and P7) displayed major conceptions that were broadly consistent across all dimensions of variation. 
Table 2

Students' dominant conceptions of ICT's role in research and dimensions of variation

\begin{tabular}{|c|c|c|c|c|c|c|c|}
\hline \multirow[t]{2}{*}{ Participant } & \multirow[t]{2}{*}{ Conception } & \multicolumn{6}{|c|}{ Dimensions of internal and external horizons } \\
\hline & & $\begin{array}{l}\text { 1. Data } \\
\text { gathering }\end{array}$ & $\begin{array}{l}\text { 2. Data } \\
\text { analysis }\end{array}$ & $\begin{array}{l}\text { 3. Colla- } \\
\text { boration }\end{array}$ & $\begin{array}{l}\text { 4. Disse- } \\
\text { mination }\end{array}$ & $\begin{array}{l}\text { 5. Infor- } \\
\text { mation } \\
\text { access }\end{array}$ & 6. Agency \\
\hline $\mathrm{P} 2$ & $\mathrm{Ab}$ & $\mathrm{Ab}$ & $\mathrm{Ab}$ & A & $\mathrm{Ab}$ & --- & $\mathrm{Ab}$ \\
\hline P4 & $\mathrm{Ab}$ & $\mathrm{Ab}$ & $\mathrm{Ab}$ & $\mathrm{Ab}$ & $\mathrm{Bc}$ & B & A \\
\hline P5 & $\mathrm{Ab}$ & A & A & $\mathrm{Ab}$ & A & $\mathrm{Ab}$ & A \\
\hline $\mathrm{P} 10$ & $\mathrm{aB}$ & $\mathrm{aB}$ & B & B & $\mathrm{aB}$ & B & $\mathrm{aB}$ \\
\hline P1 & $\mathrm{aBc}$ & A & B & $\mathrm{C}$ & B & $\mathrm{Ab}$ & $\mathrm{aB}$ \\
\hline P7 & $\mathrm{Bc}$ & $\mathrm{aB}$ & $\mathrm{aB}$ & $\mathrm{Bc}$ & Bc & --- & B \\
\hline P8 & $\mathrm{Bc}$ & Bc & $\mathrm{bC}$ & B & B & bC & B \\
\hline P9 & Bc & Bc & B & $\mathrm{abC}$ & $\mathrm{bC}$ & B & $\mathrm{aBc}$ \\
\hline P3 & $\mathrm{bC}$ & B & $\mathrm{aC}$ & $\mathrm{aB}$ & $\mathrm{bC}$ & $\mathrm{bC}$ & $\mathrm{aBc}$ \\
\hline P6 & $\mathrm{bC}$ & $\mathrm{C}$ & $\mathrm{C}$ & $\mathrm{bC}$ & $\mathrm{C}$ & $\mathrm{bC}$ & $\mathrm{bC}$ \\
\hline Legend: & Con & plementary & & Enhan & & Trar & rming \\
\hline
\end{tabular}

Third, most students had one primary conception that was usually followed by a secondary conception from one, or sometimes two, of the adjacent categories, discussed to a lesser extent. For example, three students displaying views corresponding with the complementary conception (major Category A), also discussed to some extent ICT as enhancing (minor Category b), and rarely talked about the transformative role of technologies (Category C). Four out of five students who primarily expressed the enhancing conception (major Category B), also referred to ICT's transformational potential (minor Category c) and one student referred to the complementary role (minor Category a). In contrast, two students who primarily saw the transformational role of ICT (major Category C), some of the time expressed the enhancing and only rarely the complementary conceptions (minor Category b and a, respectively). Therefore, as Table 2 shows, students' dominant conceptions were broadly similar across the dimensions of variation; however, students often expressed diverse views and, overall, their conceptions were not homogenous.

\section{Discussion and conclusions}

\section{Limitations and trustworthiness}

It is important to acknowledge some limitations of this study. First, the interview questions prompted participants to reflect on the major elements of the research knowledge cycle, but did not provide them with a detailed definition of ICT and did not ask about specific technologies, methodologies or applications. Thus, the software tools and ways of using ICT, as discussed by the participants, do not necessarily represent canonical notions of ICT, or a full range of possible ICT uses in educational technology research. However, these technologies are indicative of students' experiences and understanding of the scope of this domain, which was the main focus of this study.

Second, the study sample was relatively small and from one university. These students may represent more homogenous views than students selected from a range of universities. Nevertheless, samples with similar characteristics have been considered appropriate in other phenomenographic studies, particularly when investigating relatively new phenomena (e.g., Forster, 2013; Gonzalez, 2009; Roberts, 2003).

Further, the participants' diverse backgrounds and broad range of research topics meant that they encountered ICT outside their present degree, and in their current research, in different ways. The analytical process generated well-saturated categories, with each category and each dimension of variation represented by the experiences of at least two, but usually four or more, participants (see Table 
2). Therefore, while these results may not necessarily represent the conceptions of all research students in educational technology, they do reveal some central qualitative features and variations in how students perceive the role of ICT in research providing important original insights for current discussions about research capacity building.

\section{Students' conceptions and the nature of ICT-enhanced research}

Our study found that students' conceptions varied from complementary to enhancing to transformative. All students perceived at least some potentially valuable uses of ICT in their research domain. Nevertheless, these three categories represent fundamentally different ways in which the students made sense of ICT's role in various aspects of research: (1) as new research instruments and media that have additional or different features, but that do not change the way in research is done or its results; (2) as an enhancement of research processes and outcomes; and (3) as a change of the nature of research practices and findings. Earlier studies suggest that decisions not to use ICT for research might be related to students' inability to see ICT's utility (Carpenter, 2012; Stelma, 2010). Our findings suggest that it is also important to attend to how students see ICT's utility.

Students most often referred to various general software tools (e.g., Excel, wikis, and digital cameras). That is, their conceptions of ICT in research were mainly associated with general-purpose innovations (Gunter et al., 2009). Students' complementary views about these technologies are in line with results from other studies, which also found that research students used tools they were familiar with, and that did not challenge their current research practices (Carpenter, 2012). However, our study also shows that research students did not always conceive these familiar tools as simply fitting into conventional research practices, rather they also saw their enhancing, and even transformative, potential.

The participants in all categories mentioned similar technologies, such as Microsoft Office applications and social networking tools, and even special qualitative and statistical data analysis tools, like NVivo and SPSS. However, it was not differences in the software used, but differences in the ways in which these tools were perceived in relationship to the research practices that determined whether they were seen as complementing, enhancing, or transforming research. For example, in the quotes given earlier, P2 saw NVivo software as complementary and completely optional; in contrast, P6 saw it as transformative and absolutely invaluable. This showed that even general-purpose change in technology use could lead to transformative changes in research practices. As Orlikowski (2007) noted, the capacities of ICT tools are not fully predetermined by technologies, but emerge from human sense-making and interaction with these affordances in everyday practices. Therefore, the change in ICT is constitutively entangled with the change in practice, and cannot be understood independently from it.

Earlier studies on the adoption of ICT-enhanced research (Barjak et al, 2009; Carpenter, 2012; Dutton \& Meyer, 2009) generally paid little attention to the fact that the transformation occurs not only in technologies and how they are used, but also in the practices for which they are used. These studies often linked students' willingness to take up ICT tools with their fit into existing research practices. Our results, however, show that one of the strongest values students attach to ICT is its capacity to enhance and transform traditional ways of doing research, rather than just complement what they can already do.

Nevertheless, the implications of this finding for what students actually do should not be overstated. All the participants, particularly those who expressed the enhancing conception, raised concerns about complexity, loss of control, the possibility of technical errors, and other destabilising effects when using ICT. Such concerns are common, particularly in the middle periods of change (Hall, 1979); nonetheless they could limit students' willingness to innovate.

Further, students' views about ICT-enhanced research in relation to established practices provide a useful insight into how they perceive the link between the capacity to carry out conventional research activities and their capacity to use ICT. The affiliative view reflects a perception that conventional expertise in carrying out research activities is central, clearly defined and generally unrelated to competency with ICT. The agentic view puts much more emphasis on ICT skills, with researchers' expertise seen as including capabilities to carry out conventional research activities, but also extending these with skills to use and control ICT (e.g., use modelling software). The generative view perceives researchers' capacity to generate knowledge as distributed, dynamic and intrinsically intertwined with the powers of ICT. From 
this perspective, researchers' expertise relies on their capabilities to see and carry out research activity within the networked interplay with methodological frameworks, data, software applications and other people.

Finally, students' conceptions often varied within and across the dimensions, reflecting their diverse experiences of the phenomenon. Students' views in the transformative category, in particular, were often expressed through their awareness of distinct ICT roles for specific purposes in diverse situations. Overall, the findings indicate that students' understanding of the transformative possibilities of ICT tend to be rooted in their situated meaningful encounters with ICT in diverse research activities and collaborative work, rather than just in the routine uses of ICT or in their general awareness of large ICT's potential. (Note: Our use NVivo in this study also resulted in diverse experiences of ICT's role in research. While in some tasks NVivo was optional, it was instrumental in most complex parts of analysis; e.g., finding patterns in coded data, such as that represented in Table 2.)

\section{Implications for research capacity building and future research}

Some implications for teaching and support of research students could be suggested from these findings. First, it is a mistake to assume that all research students come with similar experiences, understandings and beliefs about the role of ICT in research. Further, ICT is likely to play distinct roles in each student's research specialisations, and they will need different methodological and technological expertise for their research projects. However, a certain level of awareness about the potential and limits of emerging inquiry approaches is essential for all future scholars as they read research done by others or work in collaborative research projects.

Our results indicate that research students with dominant conception that ICT complements research (Category A) are probably less familiar with those emerging technology-enhanced methodological approaches that are impossible without ICT, such as learning analytics, collaborative video analysis and open innovation. Various resources developed for research capacity building, particularly those that support networked experiences (e.g., Carmichael, 2011; Minocha \& Petre, 2012) and reflection on ICT’s roles (e.g., Stelma, 2010), and massive open online courses (Columbia University, 2013; University of Texas at Arlington, 2014) could offer effective instructional models for developing students' initial awareness of this domain.

Students with dominant conception that ICT enhances research (Category B), in contrast, may benefit from a more nuanced understanding about when ICT makes a difference and practical experience of how specific technologies, methods and approaches - particularly new data-driven techniques, visual data analysis tools and virtual research laboratories - can be used in their research domain. These students could particularly benefit from collaborative online projects that offer mentorship for research students, such as Distributed Research Lab (2012), and other models of research apprenticeship (Niemczyk, 2013) that embrace ICT in various aspects of research, such as data analysis and collaboration.

Students with dominant conception that ICT transforms research (Category C) are likely to be ready for methodological innovation and, thus, could benefit from opportunities to experiment with new methodologies and tools by conducing authentic research projects, and learning through contributing to open research projects. Examples of such learning opportunities could be open research projects of complex learning datasets (e.g., Dietze, 2013; ICMI, 2013).

It is important to emphasise that, in all three cases, a deep understanding of the productive roles and uses of ICT in research cannot be gained in isolation from epistemological frameworks and deep engagement with theories and methods of the domain. Therefore, students should encounter relevant ICT-enhanced methods and techniques within general research courses, rather than encounter them as an addition to traditional research expertise. Most importantly, research environments should encourage students to explore and embrace ICT-enhanced methods in their projects in ways that are meaningful for their work.

Our study provides a basis for several important research directions. We focused on how students think about the role of ICT, rather than why they think in this particular way and how they use ICT in their research projects. Further research is needed to investigate more nuanced aspects of students' conceptions, such as how these conceptions relate to various research needs and contexts. For example, 
students conducting small individual projects may have different views about the role of ICT in collaboration, compared with those conducting research in large teams. In particular, careful attention should be paid to students' research environments. Investigating the conceptions of students from different institutions and research groups could illuminate how various organisational policies, available resources, local research cultures and other contextual aspects relate with students' views. Most importantly, little is known about ICT-enhanced research capacities and the views of experienced researchers within the educational technology field. Studies of their perspectives could provide a very important foundation for future research capacity building. Our findings also provide a foundation for constructing research instruments for quantitative studies that would allow collecting data from larger numbers of participants and could assist educators to identify students' conceptions for instructional purposes.

\section{Acknowledgements}

The authors wish to thank Agnieszka Bachfischer, Peter Goodyear and Lucila Carvalho for their helpful suggestions, and Sonia Bartoluzzi and Pippa Yeoman for editorial assistance.

\section{References}

Åkerlind, G. S. (2008). An academic perspective on research and being a researcher: An integration of the literature. Studies in Higher Education, 33(1), 17-31. doi:10.1080/03075070701794775

Anderson, T., \& Kanuka, H. (2003). E-research: Methods, strategies and issues. Boston, MA: Pearson Education.

Barjak, F., Lane, J., Kertcher, Z., Poschen, M., Procter, R., \& Robinson, S. (2009). Case studies of einfrastructure adoption. Social Science Computer Review, 27(4), 583-600. doi:10.1177/0894439309332310

Beames, S. Y., Klenowski, V., \& Lloyd, M. M. (2010). Matching intention with agency: Lessons from practice. Journal of Learning Design, 3(2), 50-60. doi:10.5204/jld.v3i2.50

Bennett, S., \& Oliver, M. (2011). Talking back to theory: The missed opportunities in learning technology research. Research in Learning Technology, 19(3), 179-189. doi:10.1080/21567069.2011.624997

Biggs, J. (1999). What the student does: Teaching for enhanced learning. Higher Education Research and Development, 18(1), 57-75. doi:10.1080/0729436990180105

Borgman, C. L., Abelson, H., Dirks, L., Johnson, R., Koedinger, K. R., Linn, M. C., ... Szalay, A. (2008) Fostering learning in the networked world: The cyberlearning opportunity and challenge: A 21st century agenda for the national science foundation (Report of the NSF Task Force on Cyberlearning). Arlington, VA: NSF Task Force on Cyberlearning. Retrieved from http://www.nsf.gov/pubs/2008/nsf08204/nsf08204.pdf

Bowden, J., \& Green, P. (Eds.). (2005). Doing developmental phenomenography. Melbourne: RMIT University Press.

Bowden, J., \& Walsh, E. (Eds.). (2000). Phenomenography. Melbourne: RMIT University Press.

Brew, A. (2001). Conceptions of research: A phenomenographic study. Studies in Higher Education, 26(3), 271-285. doi:10.1080/03075070120076255

Bulfin, S., Henderson, M., Johnson, N. F., \& Selwyn, N. (2014). Methodological capacity within the field of "educational technology" research: An initial investigation. British Journal of Educational Technology, 45(3), 403-414. doi:10.1111/bjet.12145

Carmichael, P. (2011). Research capacity building in education: The role of digital archives. British Journal of Educational Studies, 59(3), 323-339. doi:10.1080/00071005.2011.599788

Carpenter, J. (2012). Researchers of tomorrow: The research behaviour of Generation Y doctoral students. Information Services and Use, 32(1), 3-17. doi:10.3233/ISU-2012-0637

Collins, J., \& Weiner, S. (2010). Proposal for the creation of a subdiscipline: Education informatics. Teachers College Record, 112(10), 2523-2536. Retrieved form http://www.tcrecord.org/content.asp?contentid=15867

Columbia University. (2013). Massive open online course “Big data in education”. Coursera. Retrieved from https://www.coursera.org/course/bigdata-edu

Dawson, S. P. (2008). A study of the relationship between student social networks and sense of community. Educational Technology \& Society, 11(3), 224-238. Retrieved from http://www.ifets.info/index.php 
Dietze, S. (2103, November 19). LAK data challenge 2014. Retrieved from http://linkedupproject.eu/2013/11/19/lak-data-challenge-2014

Distributed Research Lab. (2012). Announcing: Distributed Research Lab. Retrieved from http://www.distributedlab.net

Dutton, W. H., \& Meyer, E. T. (2009). Experience with new tools and infrastructures of research: An exploratory study of distance from, and attitudes toward, e-research. Prometheus, 27(3), 223-238. doi:10.1080/08109020903127802

Eisner, E. W. (1997). The promise and perils of alternative forms of data representation. Educational Researcher, 26(6), 4-10. doi:10.3102/0013189X026006004

Esposito, A. (2013). Neither digital or open. Just researchers. Views on digital/open scholarship practices in an Italian university. First Monday, 18(1-3). doi:10.5210/fm.v18i1.388

Ellis, R., \& Goodyear, P. (2010). Students' experiences of e-learning in higher education: The ecology of sustainable innovation. Florence, KY: Routledge.

Eynon, R. (2013). The rise of Big Data: What does it mean for education, technology, and media research? Learning, Media and Technology, 38(3), 237-240. doi:10.1080/17439884.2013.771783

Forster, M. (2013). A phenomenographic investigation into information literacy in nursing practice Preliminary findings and methodological issues. Nurse Education Today, 33(10), 1237-1241. doi:10.1016/j.nedt.2012.05.027

Gilbert, L., Jackson, K., \& di Gregorio, S. (2014). Tools for analyzing qualitative data: The history and relevance of qualitative data analysis software. In J. M. Spector, M.D. Merrill, J. Elen, \& M. J. Bishop (Eds.), Handbook of research on educational communications and technology (pp. 221-236). New York, NY: Springer.

Gonzalez, C. (2009). Conceptions of, and approaches to, teaching online: A study of lecturers teaching postgraduate distance courses. Higher Education, 57(3), 299-314. doi:10.1007/s10734-008-9145-1

Greenhow, C., \& Gleason, B. (2014). Social scholarship: Reconsidering scholarly practices in the age of social media. British Journal of Educational Technology, 45(3), 392-402. doi:10.1111/bjet.12150

Gunter, B., Rowlands, I., \& Nicholas, D. (2009). The Google generation: Are ICT innovations changing information-seeking behaviour? Oxford: Chandos.

Hall, G. E. (1979). The concerns-based approach to facilitating change. Educational Horizons, 57(4), 202-208. doi:10.2307/42924345

Harrison, N., \& Seddon, T. (2013). Living in a 2.2 world: From mapping to strategic capacity building for Australian educational research. The Australian Educational Researcher, 40(4), 403-413. doi:10.1007/s13384-013-0101-4

Hey, T., Tansley, S., \& Tolle, K. (Eds.). (2009). The fourth paradigm: Data-intensive scientific discovery. Redmond, WA: Microsoft Research.

Hine, C. (Ed.). (2006). New infrastructures for knowledge production: Understanding e-science. Hershey, PA: Information Science Publishing.

ICMI. (2013). Multimodal grand challenge. Retrieved from http://icmi.acm.org/2013/index.php?id=challenges

Jankowski, N. W. (Ed.). (2009). E-research: Transformation in scholarly practice. New York, NY: Routledge.

Knezek, G., \& Christensen, R. (2014). Tools for analyzing quantitative data. In J. M. Spector, M.D. Merrill, J. Elen, \& M. J. Bishop (Eds.), Handbook of research on educational communications and technology (pp. 203-220). New York, NY: Springer.

Larusson, J. A., \& White, B. (Eds.). (2014). Learning analytics: From research to practice. New York, NY: Springer.

Maddux, C. D. (2003). Twenty years of research in information technology in education. Computers in the Schools, 20(1-2), 35-48. doi:10.1300/J025v20n01_03

Markauskaite, L. (2010). Digital media, technologies and scholarship: Some shapes of eResearch in educational inquiry. Australian Educational Researcher, 37(4), 79-101. doi:10.1007/BF03216938

Markauskaite, L. (2011). Digital knowledge and digital research: What does eResearch offer education and social policy? In L. Markauskaite, P. Freebody, \& J. Irwin (Eds.), Methodological choice and design: Scholarship, policy and practice in social and educational research (pp. 235-252). Dordrecht: Springer.

Markauskaite, L., Kennan, M. A., Richardson, J., Aditomo, A., \& Hellmers, L. (2012). Investigating eResearch: Collaboration practices and future challenges. In A. Juan et al. (Eds.) Collaborative and distributed e-research: Innovations in technologies, strategies and applications (pp. 1-33). Hershey, PA: IGI Books. 
Markauskaite, L., \& Reimann, P. (2014). Editorial: e-Research for education: Applied, methodological and critical perspectives [Special issue]. British Journal of Educational Technologies, 45(3), 385-391. doi:10.1111/bjet.12154

Marton, F. (1986). Phenomenography - a research approach to investigating different understandings of reality. Journal of Thought, 21(3), 28-49. doi:10.2307/42589189

Marton, F. (1994). Phenomenography. In T. Husén \& T.N. Postlethwaite (Eds.), The international encyclopedia of education (2nd ed., Vol. 8, pp. 4424-4429). Oxford: Pergamon.

Marton, F., \& Booth, S. (1997). Learning and awareness. Mahwah, NJ: Lawrence Erlbaum Associates.

Marton, F., \& Pong, W.Y. (2005). On the unit of description in phenomenography. Higher Education Research \& Development, 24(4), 335-348. doi:10.1080/07294360500284706

McWilliam, E., \& Lee, A. (2006). The problem of 'the problem with educational research'. The Australian Educational Researcher, 33(2), 43-60. doi:10.1007/BF03216833

Meyer, J., Shanahan, M., \& Laugksch, R. (2005). Students' conceptions of research I: A qualitative and quantitative analysis. Scandinavian Journal of Educational Research, 49(3), 225-244. doi:10.1080/00313830500109535

Minocha, S., \& Petre, M. (2012). Handbook of social media for researchers and supervisors. London: The Open University. Retrieved from http://oro.open.ac.uk/34271

Niemczyk, E. (2013). Preparing researchers of tomorrow. In M. Kompf \& P. Denicolo (Eds.), Critical issues in higher education (Vol. 8, pp. 51-66). Rotterdam: Sense Publishers. doi:10.1007/978-946209-046-0_5

Orlikowski, W. J. (2007). Sociomaterial practices: Exploring technology at work. Organization Studies, 28(9), 1435-1448. doi:10.1177/0170840607081138

Peplau, H. E. (1957). What is experiential teaching? American Journal of Nursing, 57(7), 884-886. doi:10.1097/00000446-195707000-00028

Randolph, J. J. (2007). Multidisciplinary methods in educational technology research and development. Hämeenlinna: HAMK Press.

Reimann, P., Markauskaite, L., \& Bannert, M. (2014). e-Research and learning theory: What do sequence and process mining methods contribute? British Journal of Educational Technology, 45(3), 528-540. doi:10.1111/bjet.12146

Roberts, G. (2003). Teaching using the web: Conceptions and approaches from a phenomenographic perspective. Instructional Science, 31(1), 127-150. doi:10.1023/A:1022547619474

Romero, C., Ventura, S., Pechenizkiy, M., \& Baker, R. (Eds.). (2010). Handbook of educational data mining. Boca Raton, FL: CRC Press.

Smeyers, P., \& Depaepe, M. (2007). Educational research: Networks and technologies. Amsterdam: Springer.

Stelma, J. (2010). An ecological model of developing researcher competence: The case of software technology in doctoral research. Instructional Science, 39(3), 367-385. doi:10.1007/s11251-0109132-7

Univerity of Texas at Arlington. (2014). Data, analytics and learning. Retrieved from https://www.edx.org/course/utarlingtonx/utarlingtonx-link5-10x-data-analytics-2186

Voithofer, R. (2005). Designing new media education research: The materiality of data, representation, and dissemination. Educational Researcher, 34(9), 3-14. doi:10.3102/0013189X034009003

Corresponding author: Lina Markauskaite, lina.markauskaite@sydney.edu.au

Australasian Journal of Educational Technology (C) 2015.

Please cite as: Markauskaite, L. \& Wardak, D. (2015). Research students' conceptions of the role of information and communication technologies in educational technology research. Australasian Journal of Educational Technology, 31(4), 421-438. 